\title{
Information Technology: Market Success To Succession
}

\author{
C.S. Wright, Lincoln University, New Zealand \\ I. Dawood, Lakehead University, Canada
}

\begin{abstract}
Since commercial computers were first introduced in the early 1950s, their role, power, and importance has so expanded that the current period is often called The Information Age. Over the past decade, policy makers and the public have become progressively more concerned as success in information markets has lead to a concentration of market power that allows a few firms to dominate what is increasingly seen as a commodity essential to modern life. This paper argues that, in modern information markets, success allows domination but also creates the conditions that lead to succession - the giants of one micro-age tend to become commodity suppliers to the movers and shakers of the next micro-age. This study separates the first 50 years of The Information Age into the Hardware and the Software Micro-ages. It is suggested that the usertraining focus, of the now dawning Wetware Micro-age, will profoundly affect information markets and practises.
\end{abstract}

Keywords: Hardware, Software, Users, Costs, Cost Curves, Technology.

\subsection{INTRODUCTION}

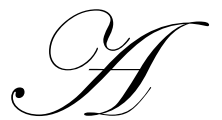

fter half a century of uninterrupted exponential growth, the information-technology (IT) industry came to a shuddering halt with the IT-market crashes of 2000-2002 that proved right sceptics who, previously, “...were derided as bozos 'who just don't get it'." (Economist, 10 May 2003, p.3).

Rather than asking what went wrong, this study looks at how things going right ultimately caused the IT-crashes of 2000-2002 to be amplified, deepened, and lengthened.

The basic problem in the IT-industry is Peer's Law The solution to the problem, changes the problem (Lyall, 1986; Rawson, 2002, p.186). In ecology, this ideal is expressed as: success for one species leads to the succession of another species. Specifically, a successful species or group of related species often create the conditions in their environment that enable succession (replacement) by unrelated species - i.e. land cleared by flood, fire, landslide, glaciation, volcanic eruption, or logging is colonized by soft plants that create soils, retain moisture, and moderate $\mathrm{PH}$, that allow for colonization by deciduous trees that shade young firs, spruce, cedar, etc., that will come to dominate the mature forest until the next clearing and renewal.

The product life-cycles of individual IT-products (i.e. introduction, take-off, maturity and decline or renewal) are so ephemeral that they are of little or no use in understanding the IT-environment. Ecologists faced with similar problems in studying natural environments gather individual species into roles within a community. In this study, IT-products and services are gathered into the roles of Hardware, Software, and Wetware. ${ }^{1}$ The development, cost, and dominance of these roles within IT are examined, over a 50-year span, using equations and parameter values that are broadly consistent with what was observed during that time - the idea is to develop a

\footnotetext{
${ }^{1}$ Wetware is the user training, experience, and knowledge - it refers to the user's brain.

Per, the internet site info.astrian.net/jargon/terms/w/wetware.html - wetware /wet'weir/n. [prob. from the novels of Rudy Rucker]: 1) The human nervous system, as opposed to computer hardware or software. "Wetware has 7 plus or minus 2 temporary registers"; 2) Human beings (programmers, operators, administrators) attached to a computer system, as opposed to the system's hardware or software.
} 
model that broadly describes the patterns in the IT-industry from 1952 to 2007 so they can be explained and the implications of their continuation can be examined.

\subsection{THE INFORMATION AGE (1952-Present)}

The first commercial computers were introduced in the early 1950s, could fill an average home (the computer on one floor and the cooling system on the other), cost over \$1 million in the currency of the day, used vacuum tubes, and had what for that time was an astounding $14 \mathrm{~K}$ of ram. Since then, the role and power of commercial computers has so expanded that modern society calls the current period The Information Age and sees it as the successor age to The Industrial Age (1700-1950).

The first 50 years of the Information Age can be separated into the Hardware and Software Micro-ages (respectively, 1952-1982 and 1982-2002). The IT-market crash of 2000-02 suggests that the IT-industry is responding neither well nor quickly enough to the dawning of a new micro-age within The Information Age. The coming Wetware Micro-age will foster the dominance of firms with (or able to develop) a user-cost focus and profoundly affect information markets and practises.

\subsection{The Hardware Micro-Age (1952-1982)}

Computer hardware ushered in The Information Age (around 1952) by become sufficiently reliable and cost effective for common use by large corporations. Since then, hardware has become ever smaller, more reliable, and more cost-effective. This progression is apparent in the sequence of quotes in Appendix 1 and the analysis of that sequence in Appendix 2. The observation that today's calculator watches have more power than the mainframes of the mid- $20^{\text {th }}$ Century is illustrative of the progress in computer hardware.

This progression of computer power has, for nearly half-a-century, been epitomized by Gordon Moore (1965) in what is now the famous Moore's Law: transistor density (i.e. computer power) doubles every two years (Economist, 10 May 2003, p.3) and its corollary: costs fall by half - i.e. the chip cost remains constant (Harrow, 2002). The original Moore's Law used 18 months as the doubling time, the modified form (two year doubling period) is examined because it is considered to be broadly more accurate over the 50 years being reviewed (Economist, 10 May 2003, p.3). The first part of Moore's law caricaturizes the computer-power progression as:

$\mathrm{C}=2^{.5(\mathrm{t}-1952)}$

Ç = Computer power in units; 1 unit is broadly and arbitrarily

set at the power of a 1952 mainframe

$1952=$ is the starting point of the hardware micro-age

$\mathrm{t}=$ the year, $\mathrm{t} \geq 1952$

The second part of Moore's Law caricaturized the progression in hardware costs as:

$H=\alpha e^{-\beta(t-1952)}$

$\mathrm{H}=$ hardware costs per unit of information flow

$\alpha, \beta=$ respectively, intercept and slope variables

A guesstimate of the value of $\beta$ is developed by dividing both sides of eqn (2) by $\alpha$ and by setting t equal to 1954 (i.e. two years into the hardware micro-age):

$0.50=\mathrm{e}^{-\beta(1954-1952)}$

$\beta=-\ln (0.50) / 2=0.34657$ 
A guesstimate of $\alpha$ 's value is formed by first using the Vance and Boutell (1975, pp.41-42) quote to guesstimate the annual-hardware costs in 1962 as $\$ 108,000$ (i.e. 12(6000+12000)/2) in 1962 \$Cdn which adjusts to $\$ 709,214$ in 2003 \$Cdn (i.e. the inflation adjustment between 1962 and 2003 is \$6.5668; Bank of Canada, July 2003). The annual cost of running a mainframe in 1962 needs to be divided by the change in computer power from 1952 to 1962 (i.e. 32.00 times, per eqn(1) above) and divided by the decrease in cost $\left(\mathrm{e}^{-\beta(1962-1952)}\right)$ to give:

$\alpha=(709,214 / 32.00) \mathrm{e}^{\beta(1962-1952)}$

$\alpha \approx \$ 709,214$

Equation (4a) implies that building a mainframe computer in 1962 cost $\$ 3,456,000$ in $1962 \$ C$ dn which is equivalent to $\$ 22,695,000$ in $2003 \$ \mathrm{Cdn}$. When these parameter values are substituted into eqn (2) the result is:

$\mathrm{H}=\$ 22.695 \mathrm{e}^{-.34657(\mathrm{t}-1952)}$

$\mathrm{H}=$ hardware costs per unit of information flow

Table 1: Hardware Cost/Unit (Equivalent to a 1952 Mainframe) in Constant 2003 \$Cdn

Per Eqn (1) Contrasted with Anecdotal Data from Selected Years (1952-2003)

\begin{tabular}{|c|c|c|c|c|c|c|c|}
\hline (a) & (b) & (c) & (d) & (e) & (f) & (g) & (i) \\
\hline 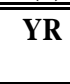 & " COMPUTER & $\begin{array}{c}\text { EST. } \\
\text { COST/UNIT }\end{array}$ & $\begin{array}{l}\text { OBS. } \\
\text { COST }\end{array}$ & $\begin{array}{c}\text { POWER }^{\wedge} \\
(\mathrm{E}=\mathrm{D} / \mathrm{C})\end{array}$ & $\begin{array}{c}\text { OBS. } \\
\text { POWER }\end{array}$ & $\begin{array}{c}\text { OBS. \$/UNIT } \\
(\mathrm{G}=\mathrm{D} / \mathrm{F})\end{array}$ & G/C\% \\
\hline 1952 & Mainframe & $\$ 709,200$ & $\$ 700,051$ & 1 & 1 & $\$ 700,051.0000$ & $0.99 \%$ \\
\hline 1962 & Mainframe & $\$ 22,160$ & $\$ 709,214$ & 32 & 32 & $\$ 22,162.9375$ & $1.00 \%$ \\
\hline 1982 & IBM PC-Туре & $\$ 21.64$ & $\$ 6,419$ & 297 & 293 & $\$ 21.9078$ & $1.01 \%$ \\
\hline 1996 & IBM PC-Туре & $\$ .1691$ & $\$ 1,407$ & 8,321 & 12,285 & $\$ 0.1145$ & $0.68 \%$ \\
\hline 2003 & IBM PC-Type & $\$ .0149$ & $\$ 978$ & 65,638 & 159,707 & $\$ 0.0061$ & $0.41 \%$ \\
\hline 2008 & Dual Core PC & $\$ .00263$ & $\$ 781$ & 311,787 & 653,568 & $\$ 0.0012$ & $0.46 \%$ \\
\hline
\end{tabular}

Estimating computer power over the 55 year span of The Information Age is difficult, especially given how input/output devices have evolved over the years. For example, how do we measure the effect of shifting from bread-board wire-programming to punch tape/cards, to keyboards/monitors, and the current movement toward voice-based input/output - these shifts reduced mean computer access-time from monthly, to less than 24 hours, to minutes, to seconds, and so forth. The addition of math co-processors in the 1970s and the recent shift to dual processors, further complicate the analysis.

Tuomi claims, in a 2003 internet article, that Moore's Law misquotes Gordon Moore and that Mr Moore keeps adjusting the law after the fact. Tuomi (2003) supports his contentions with an agglomeration of often conflicting technical jargon, history, facts, and other minutiae. However, Moore's Law has become a convenient cultural and technical icon. Thus, there is little value (other than some historic interest) in questioning whether Moore's Law is what Gordon Moore actual said or even intended to say. There is, however, great value in examining the validity of the Moore's Law constant - was it useful during the last four decades of the $20^{\text {th }}$ Century and does it continue to apply in the opening decades of the $21^{\text {st }}$ Century. As with the validity of any rule there are three possible outcomes: First) it is acceptably representative of some great idea; Second) it is too optimistic (i.e. over-estimates the progression represented); Third) it is too pessimistic (i.e. under-estimates the progression represented).

\subsubsection{Is Moore's Law Still Valid for the $21^{\text {st }}$ Century?}

The importance of Moore's Law rests not in its detail of transistors or specifics of technology, but in the broad magnificent sweep of its meaning that human-calculating power doubles each $\mathrm{N}$-years. This idea is captured in the following figure. 


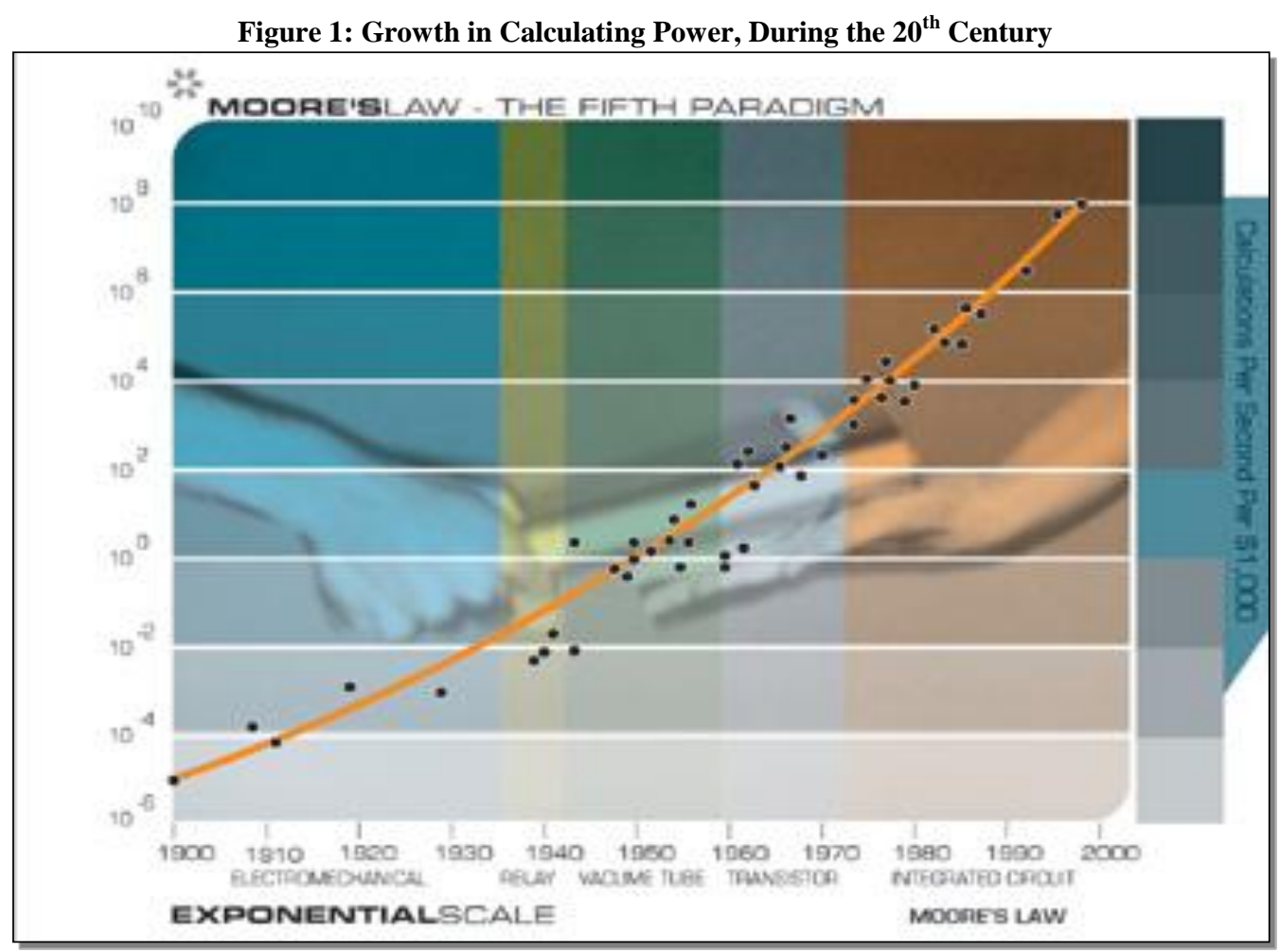

Source: Kurzweil, 2001, p.9.

Gordon Moore recently provided a mixed message when he hedged Moore's Law by asserting that "The doubling will slow down ... You really get bit by the fact that the materials are made of atoms" and then (in counterpoint) expressed his confidence that "...designers will come up with a way to have multibillion-transistor budgets" (Harrow, 2002; Dubash, 2005).

There is a common expectation that Moore's Law must fail sooner or later. However, as Chen (2003, p.16) asserts: "No exponential is forever ...but we can delay forever". While delay forever is hyperbole, any good tax accountant will confirm that many deferrals can be extended so far into the distant future that forever, for all practical purposes, is not wrong.

Tuomi (2003), to support his assertion that nearly five decades of exponential growth in computing power (Moore's Law) is only a temporary aberration, used a compost of trivial details of current technology. Tuomi (2003) cautions against Moore's Law by asserting: "True innovation is not predicable". This caution, while correct, is not particularly relevant - those who work with learning/ technology curves know that trends in innovation can be reasonably predicted, but undue reliance on predicted timing is almost as risky as not considering the cost-reducing effects of the processes such curves represent. Thus, to successfully invalidate a purported trend like Moore's Law, one must show that history does not sustain it, or (if it has been valid over a reasonable period) there is now a significant departure from the trend, or that an underlying cause of the trend either has changed or there is reasonable expectation that it will change (within a relevant period).

Figure 1 shows that, far from needing hedging, Moore's Law is too conservative. Specifically, if the semi$\log _{(10)}$ of the rise in calculation power in Figure 1 was linear, it would validate Moore's Law; a concave (to the Xaxis) curvilinear curve would indicate that Moore's Law is too optimistic; the actual convex (to the X-axis) curve indicates that Moore's Law is far too conservative and supports Kurzweil's (2001, p.9) assertion that calculation power accelerates at an accelerating rate. 
The rate of increase in acceleration is called Jerk and the idea is often used by engineers seeking to smooth the start-up of an elevator. Thus, Kurzweil's assertion that calculation power accelerates at an accelerating rate can be made more specific by renaming it Kurzweil's Constant Jerk (i.e. the acceleration of the acceleration of calculation power is constant). This idea can be tested by logging the semi-log data in Figure 1. Kurzweil's research team kindly provide the that data they used to create Figure 1 - a quick audit of that data confirmed its mathematical integrity, that the costs had been correctly indexed to 1998 \$US, and showed that it fairly represents a broad crosssection of a progression of $20^{\text {th }}$ Century calculating machines and computers. The curve in Figure 1 logged data was straightened by double logging the data to evaluate the Jerk.

$\ln \ln (\mathrm{C})=[\mathrm{a}+\mathrm{b}(\mathrm{t}-\mathrm{g})]\left[1-\mathrm{e}^{-\mathrm{c}(\mathrm{t}-\mathrm{g})}\right]$

However, because the log of a value $\leq$ nil is undefined, the data was scaled up from computations/ second/1,000 [\$US]" to those per \$ billion \$US. As this adjustment is a placeholder shift and the analysis looks at rates of change, the adjustment does not adversely affect the analysis. Equation (5) was regressed against the data from Figure 1 (Kurzweil, 2003) after the data had been shifted to allow use of the double-semi-log format in eqn (5). ${ }^{2}$ The data and the results of the regression are shown in Figure 2.

$\begin{array}{llll}\text { STATISTICAL MEASURES: } & & & \\ \text { GOODNESS OF FIT } & \text { PARAMETERS } & \text { t-STATISTIC } & \text { P-VALUE } \\ \mathrm{R}^{2}=96.09 \% & \mathrm{a}=1.6070 & 18.981 & .08466239 \\ \text { LM Statistic }=3.1921 \mathrm{E}-11 & \mathrm{~b}=0.018643 & 14.248 & .0013085 \\ \text { Durbin-Watson Statistic }=1.7856 & \mathrm{c}=0.11347 & 3.2752 & .034647 \\ \mathrm{~N}=49 & \mathrm{~g}=1896 & 1,118.5 & 1.6952\end{array}$

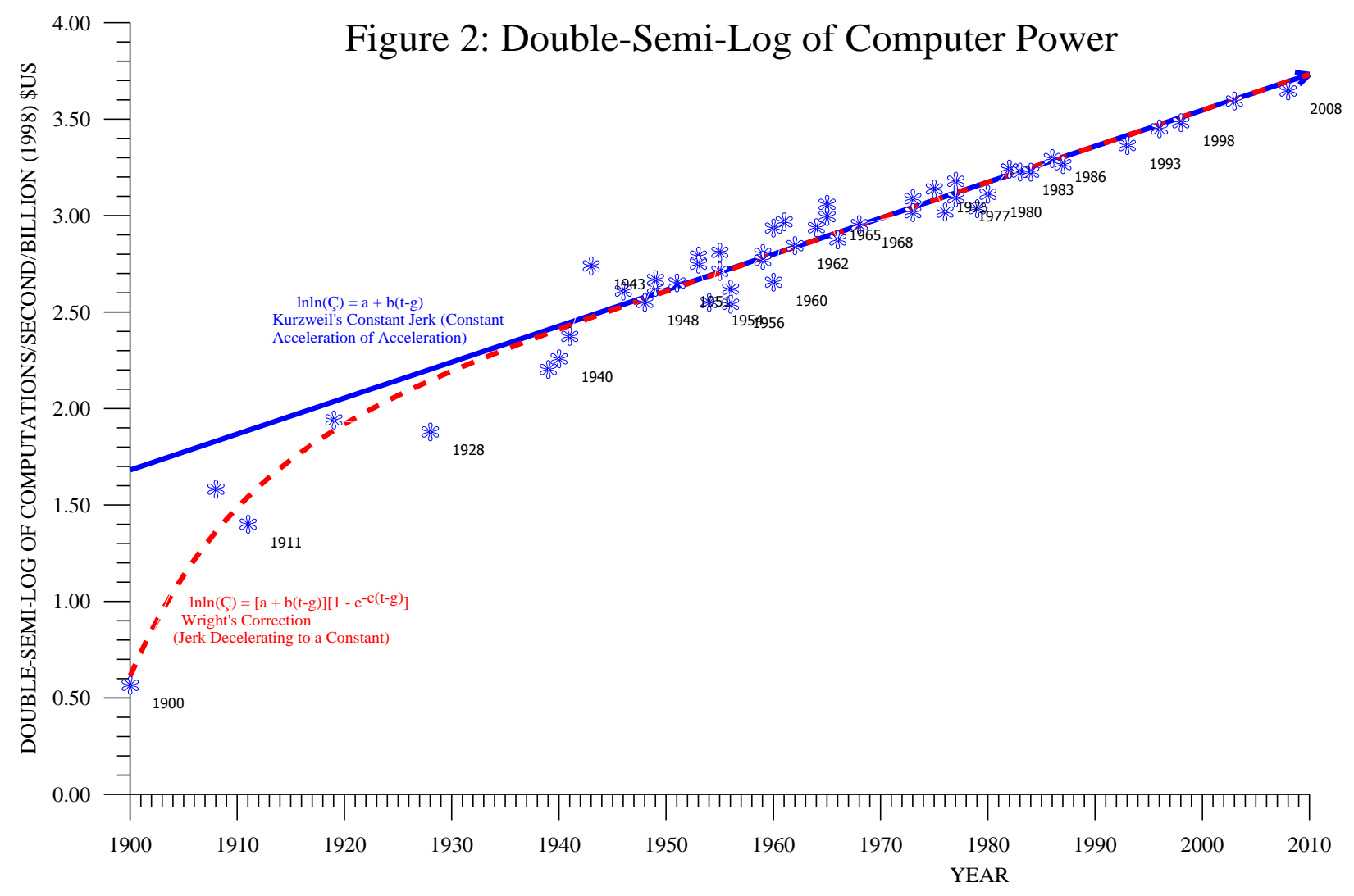

\footnotetext{
${ }^{2}$ The post-1998 data points in Figure 2 were added by personal observation.
} 
While the Jerk (i.e. the rate of increase in the acceleration) of calculating power is decreasing over time (i.e. the curve is concave to the $\mathrm{X}$-axis), it is decreasing toward a constant Jerk. Thus, Kurzweil's Constant Jerk of calculation power becomes increasingly valid, after 1950, until at the limit $(\mathrm{t} \rightarrow \infty)$ it is completely correct — it can be represented by the first term in eqn (5), to give:

$\ln \ln (C ̧)=1.6070+.018643(\mathrm{t}-1896)$

While Wright's Jerk Correction (eqn (5a)) is valid for 1900-1997 and, via extrapolation, on to the limit (as $\mathrm{t} \rightarrow \infty$ ), the correction from eqn (6) becomes increasingly irrelevant after 1950.

$\ln \ln (C ̧)=[1.6070+.011347(\mathrm{t}-1896)]\left[1-\mathrm{e}^{-.11347(\mathrm{t}-1896)}\right]$

Figure 2 and eqns (5), (5a) and (6) are very complex and difficult to understand. However, their ideas can be visually represented in terms of their effect on the doubling time of calculation power. Moore's Law asserts a constant doubling rate of every two years (i.e. per eqn $\left.(2),\left(\mathrm{e}^{.34657}\right)^{2}=2.0\right)$. The doubling time for eqn (6)Kurzweil's assertion - is estimated with:

$\mathrm{N}=(\ln \ln (2 \mathrm{C})-\mathrm{a}) / \mathrm{b}+\mathrm{g}-\mathrm{t}$

$\mathrm{N}=$ doubling time for calculation power

Given that the estimate of $\mathrm{N}$ for Wright's Jerk Correction is a relation, but not a function (i.e. $\mathrm{N}$ is on both sides of the relation), $\mathrm{N}$ must be found iteratively.

$\left.\mathrm{N}=(\ln \ln (2 \mathrm{C}) /]\left[1-\mathrm{e}^{-\mathrm{c}(\mathrm{t}-\mathrm{g})}\right]-\mathrm{a}\right) / \mathrm{b}+\mathrm{g}-\mathrm{t}$

Figure 3 shows the effect on calculation-power doubling time of Moore's Law, Kurzweil's Constant Jerk and Wright's Correction. Wright's Correction adjusts for the reality that doubling calculation power is easy when the power is very low but becomes increasingly more difficult as the power increases.

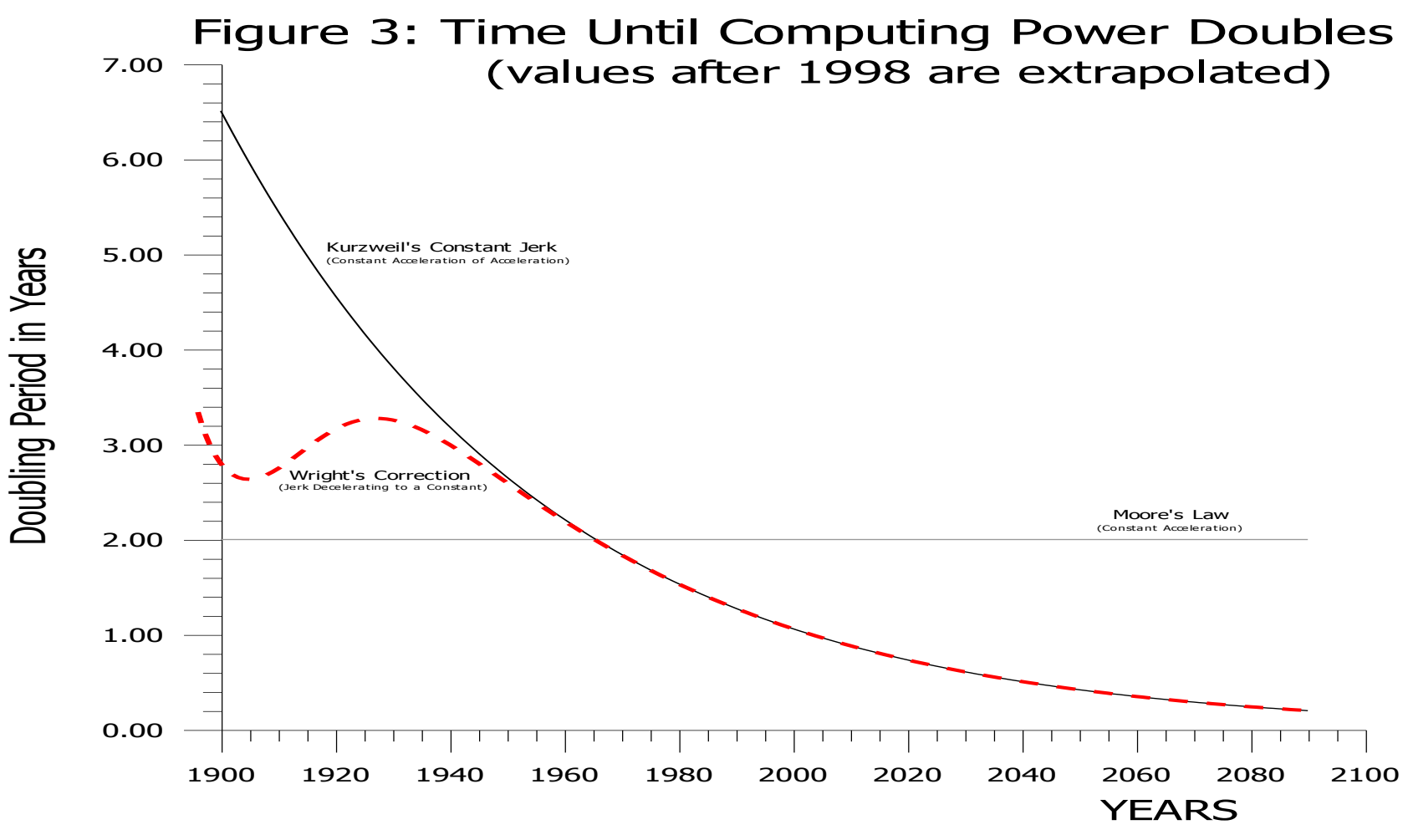


Thus, the doubling time rises (i.e. a declining Jerk) early in the $20^{\text {th }}$ Century until the offsetting effect of rising technological power reverses the trend after 1929 and Wright's Correction becomes ever more congruent with Kurzweil's Constant Jerk - the two become indistinguishable soon after the middle of the $20^{\text {th }}$ Century.

The shape of Wright's Jerk Correction between 1896 and 1906 may be an artefact of the equation form and/or the iterative technique used to calculate the doubling period - these results should not be trusted until more detailed studies are completed.

It is clear from Figure 3 that Moore's Law is profoundly inadequate - its constant must be updated frequently. Specifically, 2 years was valid in the 1960s, 1.5 years works for the 1980s, 1 year works in 2000, 10 months are needed in 2013, 5 months are needed in 2050, and 3.0 months is needed in 2078. Thus, compared with its value at the start of 2078, calculation power will double by the end of the first quarter, quadruple by the end of the second quarter, increase eight fold by the end of the third quarter, and by the end the of 2078 it is more than 16 times what it was at the start of that year.

\subsubsection{Hardware Costs (1952-2010)}

The transpose of eqn (6) (Kurzweil's Constant Jerk, in Figure 2) provides a good estimate of the pattern of decline in computer costs during The Information Age. However, the calibration of this trend has important implications for the model. Specifically, if it is calibrated to a recent point in the period (e.g. 2008), costs at the start of the period become meaninglessly large, but if it is calibrated to an early point in the period, the costs rapidly become meaninglessly small. As a compromise, the calibration is done using the cost and power of 100 IBM PCType computers in $1982-\$ 506,400$ (per Kurzweil, August 2003). The equivalent estimate in Canadian costs per Table 1 is $\$ 641,900$ or 1.2676 times Kurzweil's estimate - which is close to the 1982 exchange rate of 1.2337 $\$ C d n / \$$ US (pacific.commerce, August 2003). When the inflation rate in Canada between 1998 and 2003 of 1.1328 and Canada's Goods and Service Tax (GST) of 7.00 percent is considered, the values are within 1.25 percent of each other. When $\$ 641,900$ is multiplied by the result of eqn (6) for 1982 is $\mathrm{e}^{38.1587}$; which, when divided by eqn (6), gives:

$\mathrm{H}=\mathrm{e}^{(38.1587)} /\left[\mathrm{e}^{(1.6070+.018643(\mathrm{t}-1896))}\right]$

$\ln (\mathrm{H})=38.1587-\mathrm{e}^{(.018643 \mathrm{t}-33.7401)}$

The hardware-cost curve, in Figure 4, shows that hardware costs have declined and continue to decline at an amazing rate. However, cost declines in the other IT roles (i.e. Software and Wetware) have failed to keep pace with those in Hardware. This imbalance in cost-reduction success has real consequences for the Hardware manufactures - the relative cost of hardware dropped so low that the costs of the other IT roles now dominate the decision to acquire, replace, update or maintain IT systems. Thus, the unparalleled cost-reduction success in hardware has made hardware costs, more or less, irrelevant in the decision to acquire or upgrade an IT system.

\subsection{The Software Micro-Age (1982-2002)}

The raw calculating power and storage of hardware is meaningless without software to give users access, indexing, manipulation, analysis, communication, etc.

Early in The Information Age, programmers punched machine code on paper tape or cards to directly instruct CPUs (computer central processing units). This laborious, exacting process (e.g. it is like using pixels to form letters, to be gathered into words, and then into sentences) was costly but hardware costs were so high that software costs were seen as being incidental.

Over the first few decades of The Information Age, low-level programming-functions were hard-wired into CPUs or collected into ever more powerful programming languages - this process allowed programmers to work at ever higher levels - figuratively, the programmer's task moved from programming with pixels, to letters, to word, to sentences, to paragraphs. The object-oriented approach to programming, developed over the last few decades, is 
similar to working with pictures - as a picture is a worth a thousand words, the jump in programming power is immense. Expanding libraries of objects, object sentences, and object paragraphs that can be accessed and combined by programmers are increasing the power of software by multiple orders of magnitude.

Based on this progression of software power, the model in this paper asserts that program costs fell very slowly at the start of The Information Age, gathered momentum shortly after software costs and the need to make software use easier became visible issues in the early 1980s, and the decline in software costs is currently losing momentum - as software gains have become ever more costly to achieve. This cost pattern can be described by:

$\mathrm{S}=\mathrm{h} /\left(1+[(\mathrm{t}-\mathrm{k}) /(\mathrm{m}-\mathrm{k})]^{\mathrm{j}}\right)$

$\mathrm{h}=$ maximum software cost $=\$ 239,000$

$\mathrm{k}=$ sequence start year $=1952$

$\mathrm{m}=$ inflection year $=1993$

$\mathrm{j}=$ slope parameter $=7.0$

In the mid-1990s the drop in software costs appeared to almost go into a free-fall - thus, it is reasonable to assume the inflection point occurs in 1993. Setting $\mathrm{j}$ at 7.0 starts the visible fall in software costs in the early 1980s, when the IBM PC-type computer was introduced.

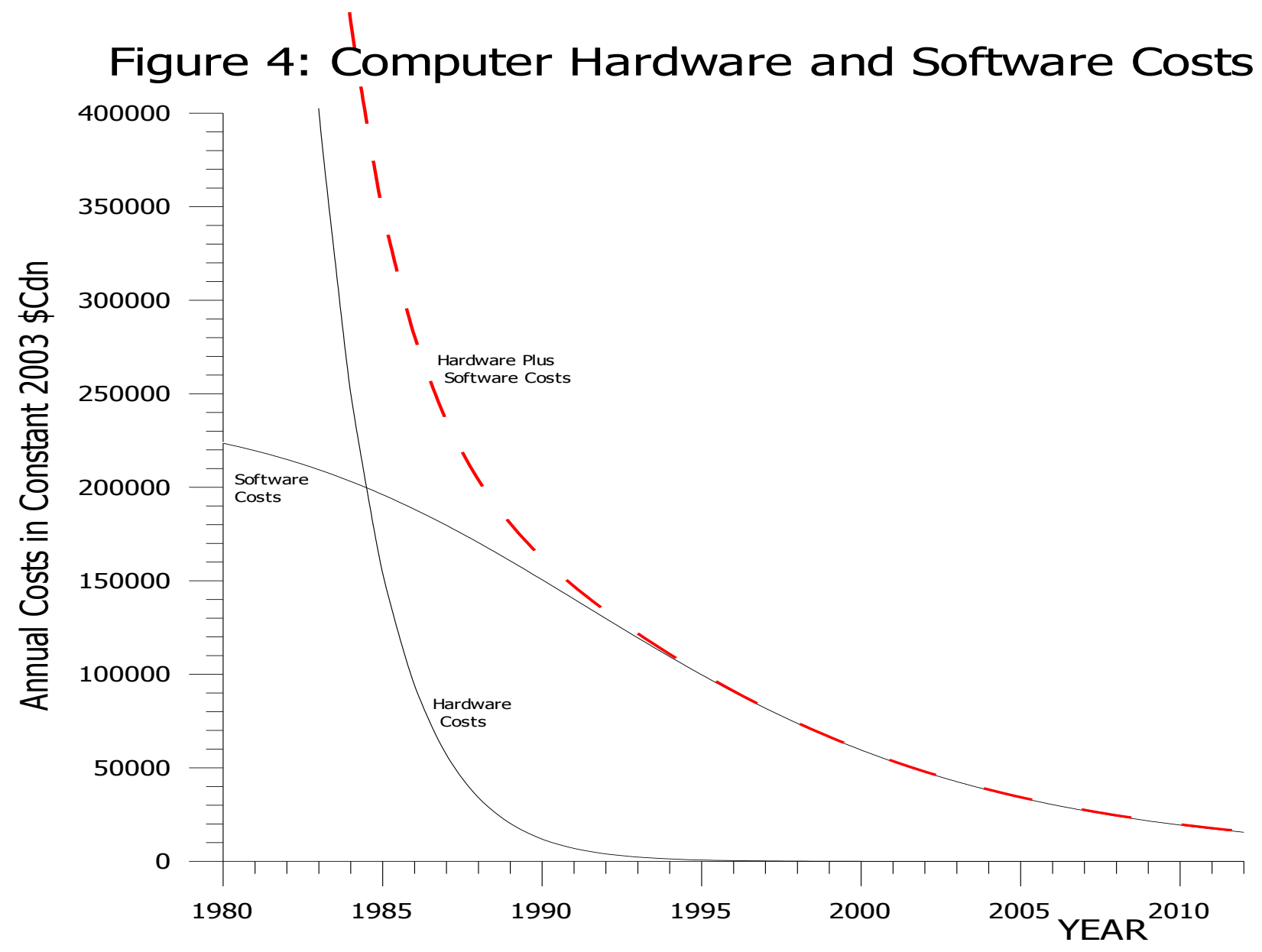

In 1982, software costs for a PC were around $\$ 3,000$ with maintenance costs (e.g. upgrades) of around $\$ 450$ a year. Assuming eight years of useful life for upgradeable software and an 18 percent interest rate, the average 
annual cost of software was around $\$ 1,200$ in $1982 \$ C \mathrm{Cdn}(\$ 400+\operatorname{Pmt}(3000,0.18,8))$ or $\$ 2,300$ in $2003 \$ C \mathrm{dn}$ (i.e. $\$ 1.9278$ in 2003 \$Cdn per $1982 \$ C$ dn; Bank of Canada, July 2003). If $\$ 230,000$ (2300 x 100) is substituted into the LHS of eqn (10) with the above parameter values, the result reorganizes to $h=\$ 295,000$, and:

$\mathrm{S}=\$ 295,000 /\left[1+.000001(\mathrm{t}-1960)^{4}\right]$

In Figure 4, after the mid-1980s, software costs increasingly overshadow hardware costs in IT-system decisions and both hardware and software costs decline exponentially. By the mid-1990s, almost everyone in ITmarkets was making money and, given constant or rising demand and costs that continued falling exponentially, ITvendors (projecting form past experience) had good reason to believe their future was so bright that they needed shades. However, the IT crashes of 2000-2002 lasted so long and hit so hard, so quickly, and with so little warning that structural issues must be involved along with the usual suspects of exuberance, imprudence and fraud. As the next subsection argues, the important structural issues afflicting IT-markets in the opening decades of the $21^{\text {st }}$ Century are those of IT-Users not IT-Suppliers. IT-Suppliers, who do not cater to those needs, risk becoming irrelevant to IT acquisition decisions.

\subsection{The Wetware Micro-Age (2002-20??)}

Wetware refers to the IT-system user - in particular, the indirect costs of making users sufficiently knowledgeable and ready to use IT hardware and software, the cost of using the system (e.g. the time spent on input, operations, and output - user time is not a free good), and the cost of interpreting, correcting, and just making sense of the computer output. During much of The Information Age, these costs were, in relative terms, so small they were ignored or buried in other costs. However, IT-suppliers who once could safely ignore user-indirect costs (or increase them by prematurely releasing buggy/kludgy software for users to Beta-test), do so today only at extreme peril. Today's users are becoming ever less shy about demanding that their IT-systems solve more problems than they create and leading-edge systems are increasingly seen as bleeding-edge systems - i.e. users bleed time and money to little or no advantage.

Horngren, et al. (2001, p.116) observe that "...today some argue that computers can contribute to information fatigue because the accessibility of low cost computing bombards users with too much information". Issues from information overload, a surfeit of choices, email spam, computer games, and just plain bewilderment rise with the power of IT. At this time, so little is known about wetware costs that, conjecture, logic, and anecdotal evidence have place of pride in the initial analysis. The basic shape of the wetware costs is assumed to be:

$\mathrm{W}=\mathrm{me}^{\mathrm{r}(\mathrm{t}-\mathrm{u})}$

$\mathrm{m}=$ scaling parameter; $\mathrm{m}=5,000$

$\mathrm{u}=$ start of PC usage; $\mathrm{u}=1982$

$\mathrm{r}=$ slope parameter; $\quad \mathrm{r}=0.1365$

Wetware costs are assumed to equal, in 2000 , the combined hardware and software costs $(\$ 59,600)$ - if that value is substituted into the LHS of eqn (11) for the year 2000, eqn (11) can be reorganized to define parameter $\mathrm{r}$ as 0.1365 . As illustrated in Figure 5, Wetware costs dominate the cost of owning a computer system, in the opening years of the $21^{\text {st }}$ Century.

It is very apparent from Figure 5 that concern over rising Wetware costs likely contributed to the chill in IT acquisitions that lead to the IT-crash of 2000-2002 and that those costs are likely to continue rising and chilling ITmarkets. If Wetware costs are not quickly tamed and contained, they will increasingly dominate IT acquisition decisions. It seems likely that incentives to further reduce hardware and software costs will, eventually, be greatly chilled by the dominant-cost effect of rising wetware costs. 


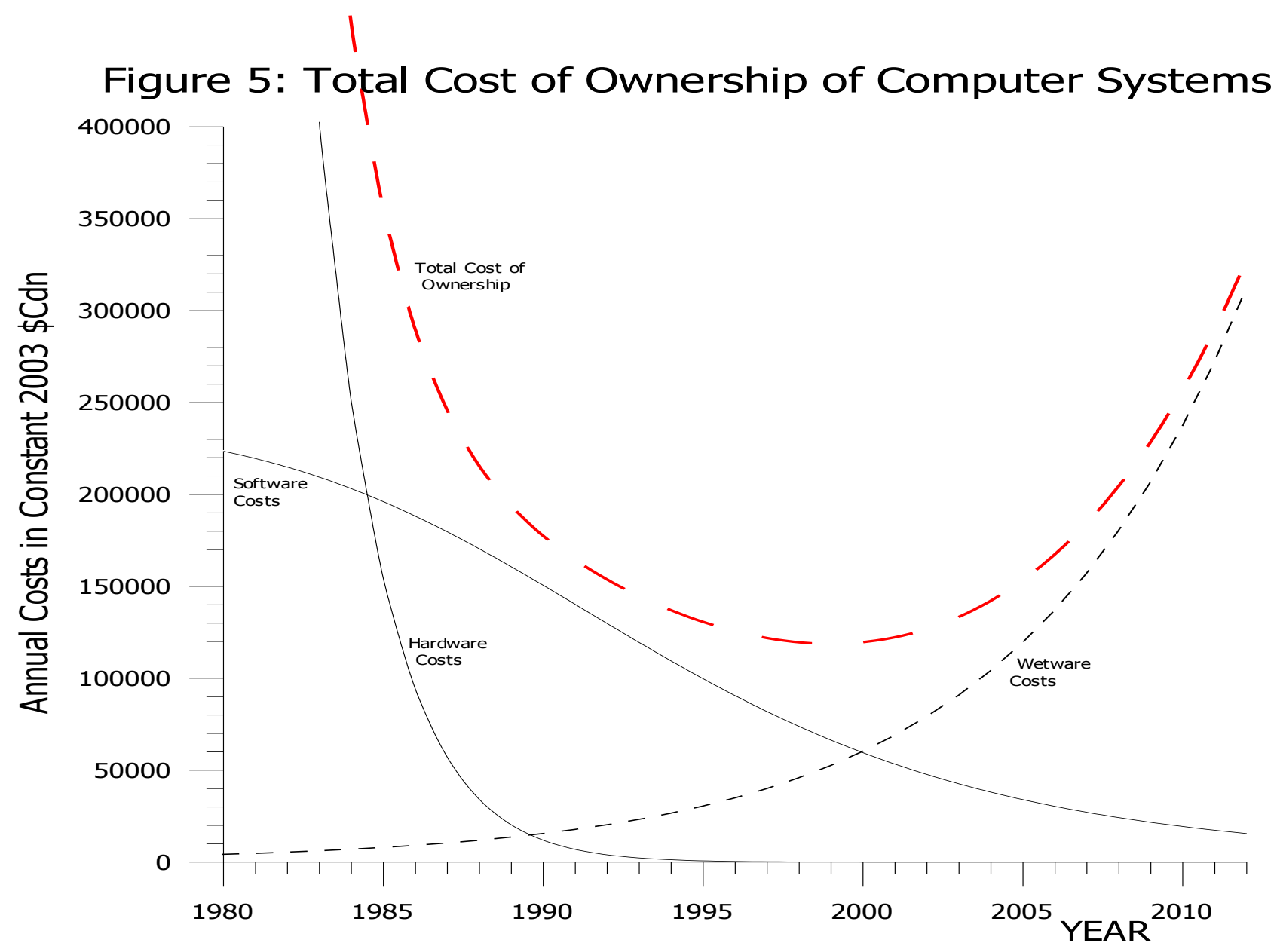

\subsubsection{The Response to Wetware Costs}

The increasing awareness of the importance of wetware costs means that solutions are being sought and will be found to mitigate and overcome their chilling effect on IT-markets. Just as some early software problems were resolved by hardwiring solutions into CPUs, many of the initial wetware solutions involve changes to hardware and software.

For example, plug-and-play now reduces the complications of setup and installation of new hardware even though the issues, bugs, and kludge of the early versions caused some wag to rename the process plug-and-pray. Other approaches include redesigning software to reduce and/or buffer information overload with system routine, gate-keeping functions, quasi-AI, and AI. Many new programs have self-learning nodes that reprogram features to user needs in a near-seamless way by learning from user responses. For example, MSWord XP has a feature that corrects what it thinks are user mistakes, but as the user reverse a correction, a heuristic feature reduces the likelihood of that correction being used in future similar circumstances - eventually, via such quasi-AI processes, programs learn (self-program) to better serve their user. A similar process is used by programs like SpamAssasin in learning to identify and filter spam by its content (Kajmowicz, 10 Aug. 2003). More and more networks are being designed around a core that evolves one step at a time in response to changes made by users - these systems adapt via the Hidden-Hand-of-User-Needs to meet the current and changing needs of users and thereby reduce the degree to which users are forced to adapt to the system. In some cases (e.g. Yahoo) a system evolves via a Delphi-like process that is far more complex, more flexible, and at a lower cost than anything that could have been designed by a team of programmers. One thing that appears to be missing in this process is the use of librarians to organize and 
index access to data and information - all too often users have to suffer through programs and/or user manuals that appear to have been written by aficionados of the arcane arts of Dungeons and Dragons.

\subsection{THE FUTURE OF COMPUTING}

While predicting the future is the domain of futurists like Kurzweil (2005), trends that are readily apparent from this study include:

- The near future belongs to IT-suppliers who can optimize the user's total-cost-of-ownership (TCO) with intuitive self-learning Delphi-like systems. This advantage will become even stronger as voice-recognition interfaces increasingly supersede keyboards, mice and menus. However, such advances (as much as they will enrich the suppliers) will only delay, not resolve, the issue of wetware costs.

- The intermediate- and long-term future is already being shaped by scientists and technicians working with neural interfaces for the physically challenged (Economist, pp.79-80, 18 October 2003) - sooner, rather than later, these interfaces will change humanity itself.

Figure 5 shows why change must and will occur - if not resolved, wetware costs will stall human progress and history teaches us that human cultures that do not progress redirect their energies and/ or stagnate, until they are absorbed into a more vibrant culture or are destroyed by external and/or internal barbarians.

\section{SUMMARY AND CONCLUSIONS}

The shortest stave in a rain barrel sets how much water it holds. Similarly, the least cost-effective of the hardware, software, or wetware roles tend to govern activity in the IT-markets. Falling hardware costs initiated The Information Age in 1952 and hardware governed IT markets until its costs fell so low that, after the early 1980s, software concerns increasingly dominated IT-markets.

The IT-market crashes of 2000-2002 may be heralding yet another nexus in IT-markets. Just as the success of the hardware giants in increasing the power of their products, while cutting costs, created favourable conditions for dominance succession by software firms, the ongoing success in hardware and software have created such powerful, versatile, and cost-effective IT-systems that user indirect-costs (i.e. wetware costs) are increasingly becoming the dominant factor in IT-investment decisions.

Wetware costs are rising so relatively rapidly that they are chilling what, in the 1990s, was the hottest market in the economy. If the wetware-cost hurdle cannot be tamed, it may strangle The Information Age.

The first tentative steps to resolve the wetware-cost hurdle have been taken in the form of adaptive systems. In the intermediate term, our culture and businesses will evolve around resolutions to the wetware-cost problem, just as its precursor cultures adapted to writing (i.e. pre-literate and literate societies and peoples are profoundly different). The long run may prove Kurzweil (2001 and 2005) right—some, if not most, humans may opt to merge with technology, so as to transcend the growth limits imposed by culture and biology.

\section{AUTHOR INFORMATION}

Prof. Chris Wright (PhD, FCPA, CMA, FRSA) is the Professor of Accounting and the Director of the Centre of Accounting and Education Research, Commerce Div., Lincoln University, NZ (profcswright@gmail.com). His research interests include: accounting theory and systems aspects of accounting, governance, economics, resource management, and IS. He is a Fellow of the Royal Society of the Arts, a Fellow of CPA Australia, and a CMA (Society of Management Accountants of Canada).

Dr. Isaam Dawood (PhD) is an Associate Professor and Head of the Information Systems Discipline at the Faculty of Business Administration, Lakehead University, Ontario, Canada (isaam.dawood@lakeheadu.ca). His research interests include: 


\section{REFERENCES}

1. Bank of Canada. July 2003. Internet Site. www.bankofcanada.ca/en/inflation calc.htm

2. Chen, M. August 2003. "Moore's Law Technology and Economics". Technology Manufacturing Group, Intel Research \& Development. Internet release at: www.intel.com/technologies.

3. Dubash, M. 2005. "Moore's Law is dead, says Gordon Moore". Techworld. Web: www.techworld.com/ opsys/news/index.cfm?newsid=3477. 13 Apr/05

4. Economist, 10 May 2003. "Paradise Lost", in: A Survey of IT Industries, The Economist, UK., 10 May 2003, pp.3-20.

5. Economist, 18 Oct. 2003. "Neuroscience: Monkey See, Monkey Do", in: Science and Technology, The Economist, UK., 18 October 2003, pp.79-80.

6. $\quad$ Financial Post. 1988. June

7. Harrow, J.R.. 2003. "The Doubling Will Slow Down." (Or will it...?)". Harrow Technology Report. 2 Dec/02. Internet site. www.theharrowgroup.com/articles/20021202/20021202.htm

8. Horngren, C., G. Sundem, J. Elliot, and H. Teall. 2001. Introduction to Financial Accounting ( $3^{\text {rd }}$ Cdn ed.). Prentice Hall, Toronto, On., Canada.

9. Kajmowicz, G. 10 August 2003. "Junk e-mail? Consider Getting an Assassin”. In: Computer Corner. The Chronicle Journal, p.A11

10. Kieso, D., J. Weygandt, V.B. Irvine, and W.H.S. Silvester. 1991. Intermediate Accounting (revised $3^{\text {rd }} \mathrm{Cdn}$ ed.). John Wiley \& Sons, Toronto, On., Canada.

11. Kurzweil, R. 2001. The Law of Accelerating Returns. KurzweilAI.net. info@kurzweilai.net. 7 March 2001.

12. Kurzweil, R. August 2003. Data Provided by e-mail communication with Kurzweil's research team.

13. Kurzweil, R. 2005. The Singularity is Near: When Humans Transcend Biology. Viking Press.

14. Levin, I., D. Rubin, and J. Stinson. 1986. Quantitative Approaches to Management $\left(6^{\text {th }}\right.$ ed). McGraw-Hill Book Company. Toronto, On., Canada.

15. Lyall, C. 1986. Murphy's Law (a Shareware Program). RR2, Kingman, Ab, Cda, T0B-2M0.

16. McWatters, C., D. Morse, and J. Zimmerman. 2001. Management Accounting: Analysis and Interpretation $\left(2^{\text {nd }} e d\right)$. McGraw-Hill Book Company. Toronto, On., Canada.

17. Moore, G. 1965. "Cramming More Components onto Integrated Circuits". Electronics, Vol.38, \# 8, 19 Apr/65. Web: download.intel.com/research/silicon/moorespaper.pdf. (Accessed: 17 Mar/08).

18. Pacific.Commerce. August 2003. "Pacific Exchange Rate Service. An Internet site. pacific.commerce.ubc.ca/xr/USDpages.pdf

19. Rawson, H. 2002. Unwritten Laws: The unofficial Rules of Life as Handed Down by Murphy and Other Sages. Castle Books. Edison, N.J.

20. Tuomi, I. "The Lives and Death of Moore's Law". First Monday. A Peer-reviewed internet journal. http://firstmonday.org/issues/issue7_11/tuomi/index.html

21. Vance, L. and W. Boutell. 1975. Principles of Auditing. The Dryden Press, Hinsdale, Il.

22. White, K.J. 1993. Shazam User's Reference Manual V.7.0. McGraw-Hill. Toronto, Canada. 


\section{APPENDIX 1: Sequence of Quotes on the Rising Cost-Effectiveness of Computers}

At the dawn of The Information Age (1948) IBM asserted "The computer has no commercial future." (Attributed to IBM by White, 1993, p.413).

"Where a calculator on the ENIAC is equipped with 18,000 vacuum tubes and weighs 30 tons, computers in the future may have only 1,000 vacuum tubes and perhaps weigh only 1.5 tons." (Attributed to a March 1949 issue of Popular Mechanics, by White, 1993, p.323).

"By 1950 the real constraints to the development of the computer were technological; thus most of the effort in the early 1950s was on hardware....It was roughly 1953 when large numbers of businesses started to purchase computers for data processing." (Levin, et al., 1986, pp.32-33).

"At first, computers were too expensive for routine business data processing and accounting. However, since 1950, the cost of computing has been cut in half approximately every three years." (Horngren, et al., 2001, p.116).

"Among the business-oriented computers which were available in the early 1960's, the IBM 1401, the Honeywell 400, the RCA 301, the GE 225, the NCR 315, and the Burroughs 280 were typical examples....The speed at which these machines could accept punched cards varied from 600 to 1,000 cards per minute, and they could output printed lines (of between 100 and 132 characters per line) at the rate of 600 to 1,000 lines per minute. The internal storage capacity of these computers was...between 4,000 and 16,000 characters of internal storage [4 to $16 \mathrm{~K}$; and] ...the rental rates ranged between $\$ 6,000$ and $\$ 12,000$ a month." (Vance and Boutell, 1975, pp.41-42).

In "the late 1970 's, ....computers were primitive by today's standards. They offered only 16 kilobytes of internal memory but nevertheless cost from $\$ 15,000$ to $\$ 30,000$." (Horngren, et al., 2001, p.116).

"There is no reason for any individual to have a computer in their home" (Attributed to a 1977 comment made by Ken Olson, president of DEC Corp., by White, 1993, p.433).

Per “...the Financial Post (June, 1988) a microcomputer which cost $\$ 10,000$ today has more power than a $\$ 5$ million mainframe built about a decade ago." (Kieso, et al., 1991. p.103).

"By the mid 1990s a small business could buy a computer with more than 100 megabytes of [internal] memory for less than $\$ 1,000$. The computing power that once filled a room can now be easily carried in a briefcase. (Horngren, et al., 2001, p.116).

"The computing power of a digital watch today exceeds the computing power of the largest calculating machines just 50 years ago." (McWatters, et al., 2001, p.5). 


\section{APPENDIX 2: Computer Cost/Power Estimates During The Information Age}

In 1952, the observed cost of a computer was around $\$ 1$ million in $1952 \$ C d n$ or $\$ 7,266,300$ in $2003 \$$ Cdn (i.e. $\$ 7.2663$ in 2003 \$Cdn per 1952 \$Cdn; Bank of Canada, July 2003). This implies an annual cost of $\$ 700,051$ - i.e. the payment generated by a 15 year annuity (mainframes have a longer life than the later PCs) with a $\$ 7,266,300$ present value and a 5.0 percent interest rate).

In 1962, the observed cost (per eqn (4), above) was $\$ 709,214$; as there is no observed power, the estimated value of 32 is used for continuity. The high accuracy of the result is expected - given that $\alpha$ 's value (for eqn (2), section 2.1) was estimated from the 1962 observed data.

In 1982, the cost of an IBM PC was around \$6,800 or \$13,109 in 2003 \$Cdn (i.e. \$1.9278 in 2003 \$Cdn per 1982 $\$ C d n$; Bank of Canada, July 2003). This implies an annual cost of $\$ 6,419$ (i.e. the payment generated by a three year annuity with a $\$ 13,109$ present value and an 18 percent interest rate).

The first IBM PC-Type computers had $128 \mathrm{~K}$ of ram which is 9.14 times the $14 \mathrm{~K}$ found in many of the 1962 mainframe computer which, in turn, were 32 times more powerful than the 1952 mainframe computers - thus, as a broad first approximation, 1982 IBM PC-type computers were 293 times more powerful than the 1952 mainframes.

In 1996, per Horngren, et al. (2001, p.116), the cost of a computer box was $\$ 1,000$. However, $\$ 2,000$ was needed for peripherals (e.g. printer, monitor, and modem) for a total cost of \$3,000 in 1996 \$Cdn or \$3,499 in 2003 \$Cdn (i.e. \$1.1662 in 2003 \$Cdn per 1996 \$Cdn; Bank of Canada, July 2003). This implies an annual cost of $\$ 1,407$ (i.e. the payment generated by a three annuity with a $\$ 3,499$ present value and a 10 percent interest rate).

As a crude estimate of the change in power - computers in 1996 ran at around $200 \mathrm{MHz}$ which is 41.93 times the $4.77 \mathrm{MHz}$ of the $1982 \mathrm{PCs}$ which were 293 times more powerful than the 1952 mainframes thus, as a broad first approximation, in 1996, IBM-PC-type computers were 12,285 times as powerful as 1952 mainframes.

In 2003, a top-of-the-line PC system with peripherals can be bought for $\$ 2,600$. This implies an annual cost of $\$ 973$ (i.e. the payment generated by a three year annuity with a $\$ 2,600$ present value and a 6 percent interest rate).

As a crude estimate of the change in power - computers in 2003 ran at around $2.6 \mathrm{Gig} \mathrm{Hz}$ which is 545.07 times the $4.77 \mathrm{MHz}$ of the $1982 \mathrm{PCs}$ which were 293 times more powerful than the 1952 mainframes - thus, as a broad first approximation, in 2003, IBM-PC-type computers are 159,706 times as powerful as 1952 mainframes.

In 2008, the standard computer with screen and printer costs around $\$ 1,800$ (implying an annual cost of $\$ 650$ ) and has a dual-Core Quad (4 processors) $2.66 \mathrm{Gig} \mathrm{Hz}$ which is equivalent to 2.66 x $4=10.64 \mathrm{Gig} \mathrm{Hz}$. which is 2,231 times the $4.77 \mathrm{MHz}$ of the $1982 \mathrm{PC}$ which were 293 times more powerful than the 1952 mainframes - thus, as a broad first approximation, in 2008, the IBM-PC-type computers are 653,568 times as powerful and 1952 mainframes. However, other factors are also increasing in power - the Ram in a $2008 \mathrm{PC}$ computer is $4 \mathrm{~GB}$ compared to with the $1 \mathrm{~GB}$ of 2003 and the $14 \mathrm{~KB}$ of 1952 . Thus, in terms of ram, an average 2008 computer is four times more powerful than an average 2003 computer and 285,714 times more powerful than a 1952 mainframe. 